\title{
MicroRNA Deregulation in Anaplastic Thyroid Cancer Biology
}

\author{
Cesar Seigi Fuziwara and Edna Teruko Kimura \\ Department of Cell and Developmental Biology, Institute of Biomedical Sciences, University of São Paulo, \\ Avenida Professor Lineu Prestes 1524, Room 414, CEP, Butantã, 05508-000 São Paulo, SP, Brazil \\ Correspondence should be addressed to Edna Teruko Kimura; etkimura@usp.br
}

Received 30 May 2014; Accepted 29 July 2014; Published 19 August 2014

Academic Editor: Giuliana Salvatore

Copyright (C) 2014 C. S. Fuziwara and E. T. Kimura. This is an open access article distributed under the Creative Commons Attribution License, which permits unrestricted use, distribution, and reproduction in any medium, provided the original work is properly cited.

\begin{abstract}
Anaplastic thyroid cancer (ATC) is among the most lethal types of cancers, characterized as a fast-growing and highly invasive thyroid tumor that is unresponsive to surgery and radioiodine, blunting therapeutic efficacy. Classically, genetic alterations in tumor suppressor TP53 are frequent, and cumulative alterations in different signaling pathways, such as MAPK and PI3K, are detected in ATC. Recently, deregulation in microRNAs (miRNAs), a class of small endogenous RNAs that regulate protein expression, has been implicated in tumorigenesis and cancer progression. Deregulation of miRNA expression is detected in thyroid cancer. Upregulation of miRNAs, such as miR-146b, miR-221, and miR-222, is observed in ATC and also in differentiated thyroid cancer (papillary and follicular), indicating that these miRNAs' overexpression is essential in maintaining tumorigenesis. However, specific miRNAs are downregulated in ATC, such as those of the miR-200 and miR-30 families, which are important negative regulators of cell migration, invasion, and epithelial-to-mesenchymal transition (EMT), processes that are overactivated in ATC. Therefore, molecular interference to restore the expression of tumor suppressor miRNAs, or to blunt overexpressed oncogenic miRNAs, is a promising therapeutic approach to ameliorate the treatment of ATC. In this review, we will explore the importance of miRNA deregulation for ATC cell biology.
\end{abstract}

\section{Introduction}

Anaplastic thyroid cancer (ATC) is the most lethal histotype of thyroid cancer, responsible for more than one-third of thyroid cancer-related deaths [1]. The fast-growing nature of this type of cancer and its refractoriness to radioiodine treatment due to tumors not concentrating iodine limit the efficacy of therapeutic interventions [2]. Thus, ATC patients display a rapidly progressive disease that may cause death within six months [3].

ATC's clinical pathology is characterized by the aggressive behavior of cancer cells, which results in a rapid enlargement of the neck tumor to invade adjacent tissue and migrate as distant metastases, usually with secondary sites in the lungs, bone, and brain [4]. During this process, activation of epithelial-to-mesenchymal transition (EMT) is a key feature of anaplastic transformation. Moreover, loss of expression of differentiation markers (iodine metabolizing genes) and, consequently, loss of iodine uptake are markers of this process that negatively impact on ATC radioiodine responsiveness.
Unlike the differentiated histotypes of thyroid cancer, papillary thyroid cancer (PTC) and follicular thyroid cancer (FTC) that show a single driver mutation pattern, the tumorigenesis of ATC is not completely understood: it may arise de novo or from a preexisting well-differentiated cancer (PTC/ FTC). The most prevalent genetic alterations in ATC are mutations in the TP53 gene at codon 273 as observed in more than $70 \%$ of ATC samples $[5,6]$, leading to 553 loss of function. Moreover, mutations in the telomerase gene (TERT) are frequently seen in aggressive thyroid cancers, including in poorly differentiated and anaplastic thyroid cancers [7, 8], and lead to increased transcriptional activity of TERT. However, additional mutations in MAPK signaling (RAS and BRAF genes), in PI3K signaling (PIKCA and PTEN), and in Wnt signaling ( $\beta$-catenin and APC) have also been detected in ATC [9-12].

Animal models have contributed to an understanding of the molecular transformation of ATC. The thyroid cancer progression hypothesis is corroborated by a transgenic mouse model for the early activation of the $B R A F^{T 1799 A}$ oncogene 


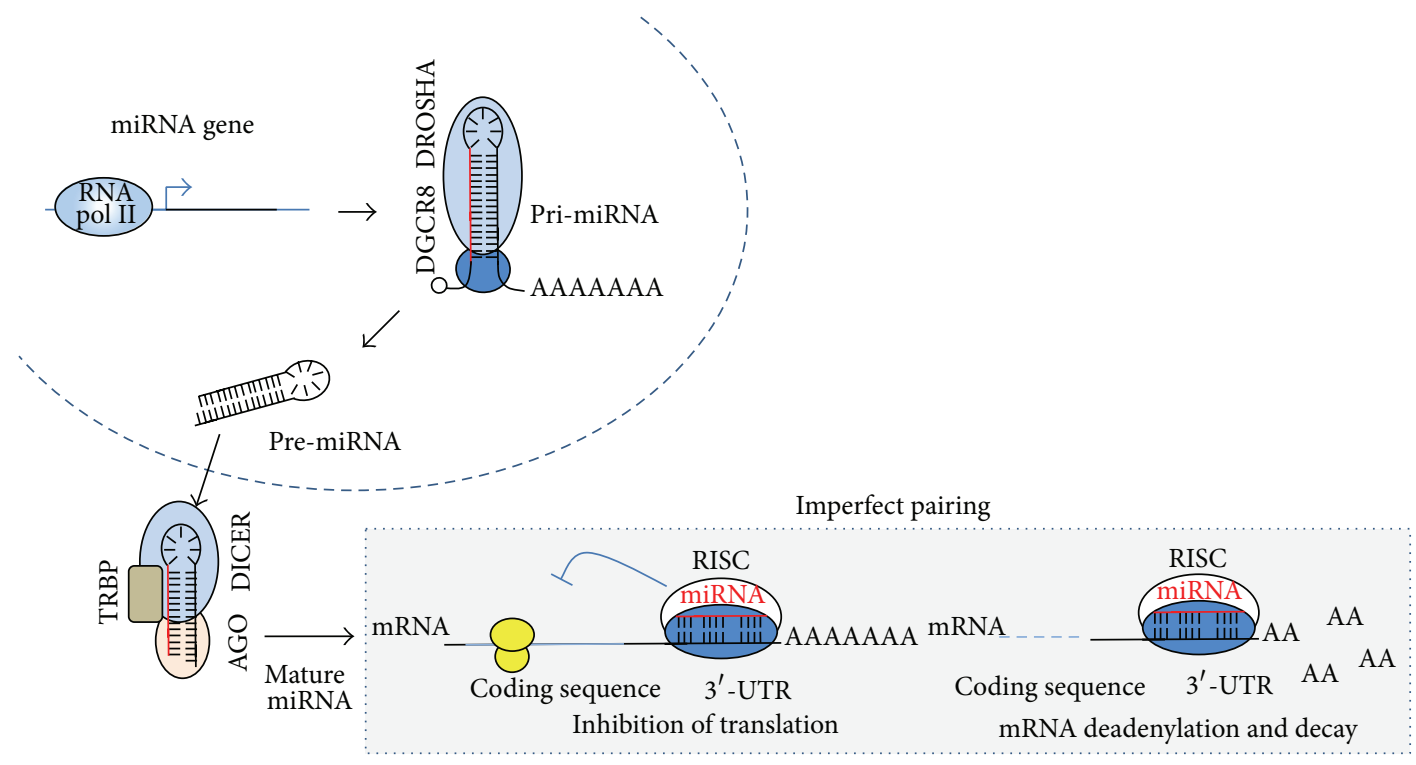

FIGURE 1: Biogenesis of miRNA. Transcription of miRNA by RNA polymerase II yields a long primary transcript (pri-miRNA) that contains a cap $5^{\prime}$ and poly-A tail. The complex DROSHA/DGCR8 cleaves pri-miRNA and gives rise to an miRNA precursor (pre-miRNA) that is exported to the cytoplasm and further processed by DICER endonuclease. An miRNA duplex associates with the RISC complex and retains the mature strand of miRNA. This complex directs imperfect binding to $3^{\prime}$-UTR region of target mRNA, leading to a reduction in protein levels via translation blockage and mRNA deadenylation and decay.

restricted to the thyroid gland (Tg-BRAF) that is affected by high penetrance PTC that undergoes temporal dedifferentiation [13]. Molecular analysis of Tg-BRAF mice-derived tumors reveals the deregulation of TGF $\beta$ signaling upon prolonged stimulation of the BRAF oncogene, with enhanced TGF $\beta$ signaling transduction and a shift to EMT by ZEB1 and ZEB2 transcription factor activation [14]. Another transgenic model with BRAF activation in adult mice also gives rise to differentiated thyroid cancer; however, progression to ATC requires TP53 gene deletion [15], corroborating the multistep cancer progression hypothesis for ATC. A mouse model harboring defective PI3K signaling gives rise to aggressive thyroid cancer. Transgenic mice carrying deletions of Pten and TP53 [Pten, p53] ${ }^{\text {(thyr-/-) }}$ develop ATC with loss of expression of the thyroid transcription factors, Nkx2-1, Pax-8, and Foxe1, and thyroid differentiation markers, Nis, Tpo, $\mathrm{Tg}$, Tshr, and Duox [16]. [Pten, p53] (thyr-/-) $^{\text {mice thyroid tumors }}$ undergo TGF $\beta$ signaling induced EMT and demonstrate increased pSMAD2 and vimentin levels, but loss of E-cadherin expression.

Recently, a pivotal role for microRNAs (miRNAs) in cancer has emerged with increasing evidence showing that they may drive and potentiate oncogenesis. The miRNAs are a class of small noncoding RNAs ( $\sim 20 \mathrm{nt})$ that regulates posttranscriptional gene expression. These miRNAs are transcribed as long primary RNAs that undergo sequential cleavages by Drosha and Dicer ribonucleases in the nucleus and cytoplasm, respectively, to yield mature miRNA. In turn, mature miRNA associates with the protein complex RISC (RNA-induced silencing complex), which directs pairing with the $3^{\prime}$-UTR region of target mRNAs. Imperfect pairing leads to translational blockage of target mRNA and, also, mRNA deadenylation and decay (Figure 1).

Essentially, miRNA deregulation in cancer is oncogenic (oncomiR) under two different conditions: (a) when overexpressed, miRNAs may block tumor suppressor gene translation or (b) when underexpressed, miRNAs may derepress protooncogene mRNA translation (Figure 2).

Deregulation of miRNA in thyroid cancer was initially described by He et al. in a group of PTCs [17]. The same group of upregulated miRNAs, such as $m i R-146 b, m i R-221$, and $m i R-222$, is commonly detected in ATC and in differentiated thyroid cancers (papillary and follicular histotypes) [18] and also in a fraction of benign nodules $[17,19]$, indicating that persistent expression of these miRNAs may be necessary to maintain tumorigenesis. However, ATC also shows exclusive reduction of certain miRNAs with tumor suppressor properties, indicating a role for these miRNAs in tumor aggressiveness (Figure 3). Investigating tumour samples from a group of ten ATC patients by microarray analysis, the seminal study of Visone et al. [20] revealed the repression of $m i R-30 d, m i R-$ $125 b, m i R-26 a$, and $m i R-30 a-5 p$. In addition, another study showed a reduction of several members of the let-7 and $m i R-$ 200 family of miRNAs [21] and overexpression of $m i R-221$, $m i R-222$, and $m i R-125 a-3 p$.

In this review, we will explore some aspects of the deregulated miRNA found in anaplastic thyroid cancer to address the molecular biology and signaling pathways implicated in the clinical-pathological characteristics of this type of cancer (Table 1). 
TABLE 1: Validated targets for deregulated miRNAs in ATC.

\begin{tabular}{|c|c|c|c|c|c|c|}
\hline \multicolumn{2}{|c|}{ miRNAs } & \multicolumn{3}{|c|}{ Validated targets } & \multirow{2}{*}{$\begin{array}{l}\text { Cellular processes } \\
\text { EMT and proliferation }\end{array}$} & \multirow{2}{*}{$\begin{array}{c}\text { References } \\
{[21,67]}\end{array}$} \\
\hline \multirow{5}{*}{ Downregulated miRs } & miR-200 family & ZEB1 & ZEB2 & $\beta$-Catenin & & \\
\hline & $m i R-30$ family & Beclin1 & $\mathrm{EZH} 2$ & VIM & $\begin{array}{l}\text { Autophagy, chromatin } \\
\text { condensation, and EMT }\end{array}$ & {$[30,33,67]$} \\
\hline & let-7 family & RAS & HMGA2 & LIN28 & $\begin{array}{l}\text { Proliferation, histone } \\
\text { modification, and stemness }\end{array}$ & {$[67,68]$} \\
\hline & $m i R-25$ & $\mathrm{EZH} 2$ & BIM & KLF4 & $\begin{array}{l}\text { Chromatin condensation and } \\
\text { apoptosis }\end{array}$ & {$[30,67]$} \\
\hline & $\operatorname{miR}-125$ & MMP1 & HMGA2 & LIN28A & $\begin{array}{l}\text { Invasion, histone modification, } \\
\text { and stemness }\end{array}$ & {$[20,67,69]$} \\
\hline \multirow{3}{*}{ Upregulated miRs } & $m i R-221 / m i R-222$ & p27 & RECK & PTEN & Cell cycle, growth, and invasion & {$[20,67]$} \\
\hline & miR-17-92 cluster & $\mathrm{p} 21$ & TIMP3 & PTEN & Cell growth and invasion & {$[45,67]$} \\
\hline & $m i R-146 a / m i R-146 b$ & $\mathrm{NF} \kappa \mathrm{B}$ & THRB & SMAD4 & $\begin{array}{l}\text { Cell differentiation, proliferation, } \\
\text { and invasion }\end{array}$ & {$[52,67,70,71]$} \\
\hline
\end{tabular}

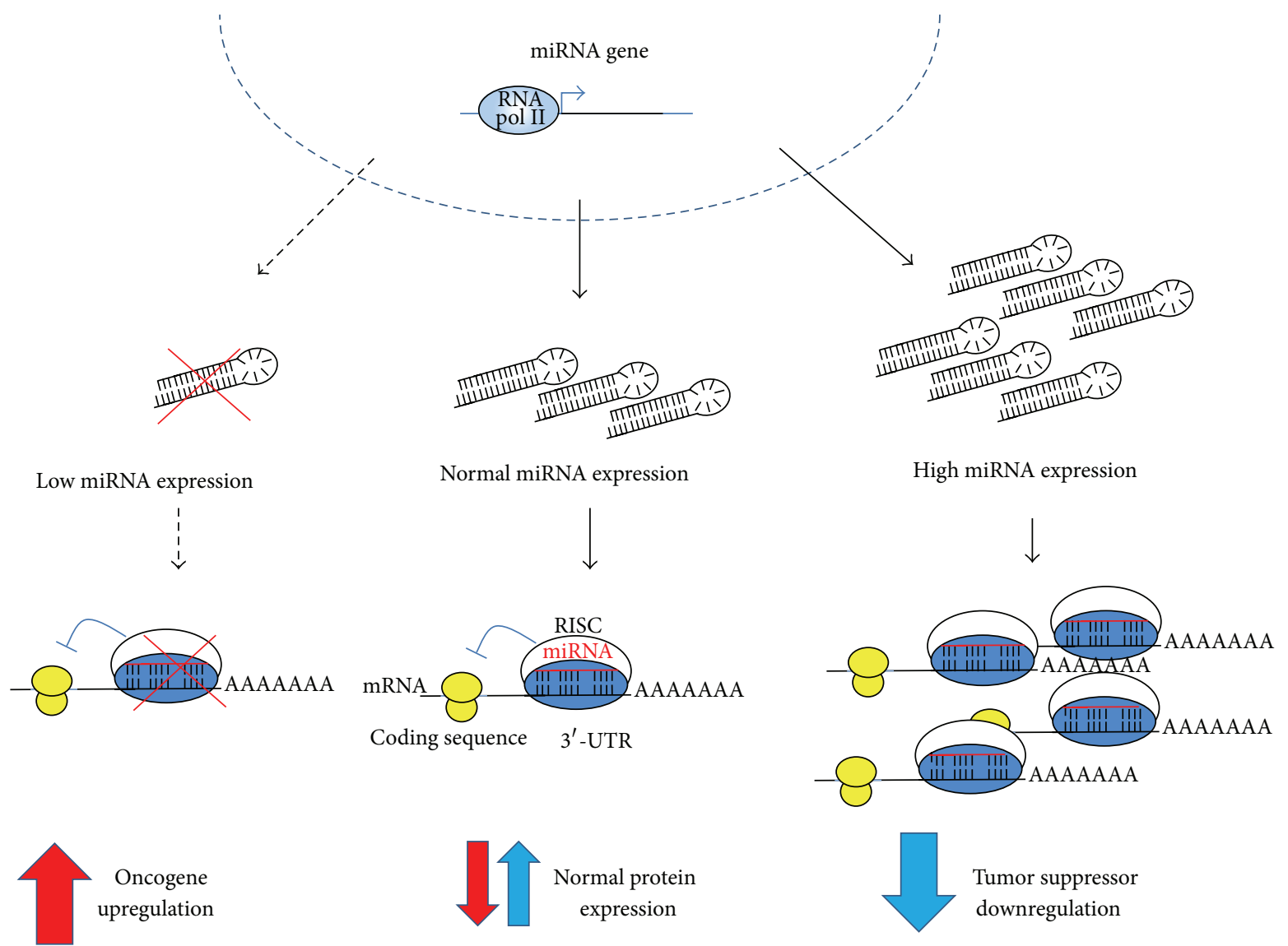

FIgURE 2: Some miRNAs act as oncomiRs. Deregulation of miRNA changes physiological protein level balances and enhances the oncogenic process where (1) low expression of an miRNA may enhance protein translation of an oncogenic protein or (2) high expression of an miRNA may repress the translation of a tumor suppressor gene. Both situations may occur concomitantly in cancer as observed in anaplastic thyroid cancer.

\section{Downregulated miRNAs in ATC}

Specific miRNAs are reduced in thyroid cancer, such as the let-7 family, but other miRNAs, such as the $m i R-200$ and $m i R$ 30 families, are exclusively downregulated in ATC, indicating that the latter miRNAs may play a role in the acquisition of more aggressive tumor characteristics (i.e., enhanced cell invasion and migration).

2.1. miR-200 Family. The miR-200 family is composed of the $m i R-200 a, m i R-200 b$, and $m i R-200 c$ genes, which are usually downregulated in ATC [21]. The miR-200a and miR-200b 


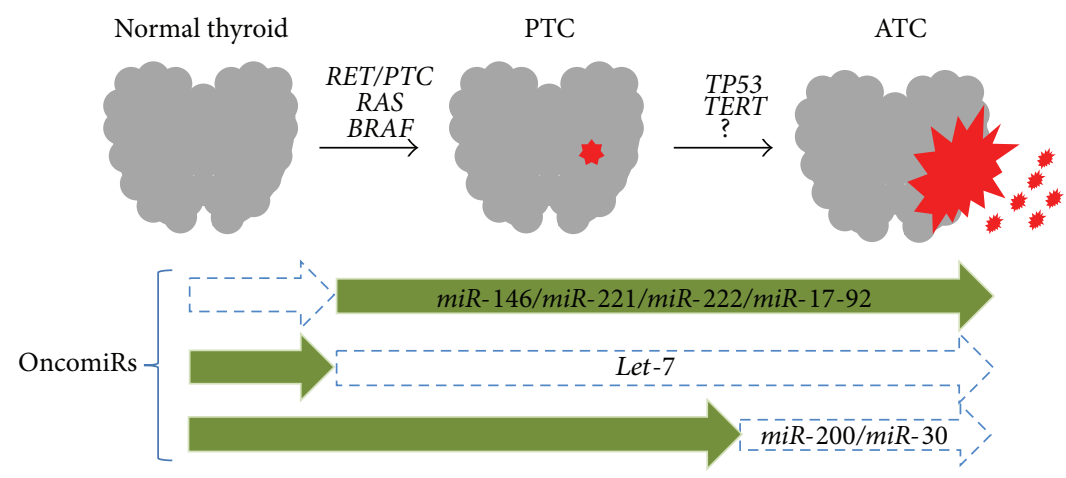

Figure 3: Thyroid oncogenesis and miRNAs. Activation of MAPK oncogenes by mutations or rearrangements leads to PTC. Progression to ATC may be associated with the acquisition of additional genetic alterations such as TP53 mutations. Deregulation of miRNA occurs during thyroid oncogenesis, with specific upregulation of miRNAs such as $m i R-146, m i R-221, m i R-222$, and $m i R-17-92$ cluster, and loss of let-7 expression, in both PTC and ATC. Exclusive downregulation of miRNAs, such as miR-200 and miR-30, is observed in ATC.

genes make up a cluster located on chromosome 1 , while the $m i R-200 c$ gene is located on chromosome 12. An important transcriptional activator of $m i R-200$ is p53, which binds to the promoter region of $m i R-200 c$ at multiple sites. Interestingly, a TP53 mutation at a DNA binding domain as present in ATC impairs downstream transcriptional activation of $m i R$ 200 [22]. Moreover, p53 is an important controller of tumor suppressor miRNAs, such as those of the $m i R-34$ family, and also influences miRNA processing [23], besides having a classical role in DNA repair and genomic stability. Another signaling pathway that influences $m i R-200$ expression is the EGF pathway. Overexpression of the EGF receptor, EGFR, is observed in ATC [24], while EGFR knockdown in ATC cells restores $m i R-200$ expression and represses the expression of mesenchymal markers [25]. Classically, TGF $\beta$ signaling induces epithelial-to-mesenchymal transition (EMT), via the transcriptional activation of ZEB1 and ZEB2 [21], inducing a mesenchymal phenotype, with the expression of vimentin and repression of E-cadherin as observed in ATC. Interestingly, the miR-200 family is an important regulator of the EMT process by regulating ZEB1 and ZEB2 protein levels. Downregulation of $m i R-200$ in ATC would potentiate the TGF $\beta$-mediated EMT switch and enhance aggressiveness.

2.2. $m i R-30$ Family. The miR-30 family of tumor suppressor miRNAs is composed of five members: $m i R-30 a, m i R-30 b$, $m i R-30 c, m i R-30 d$, and $m i R-30 e$. Downregulation of the $m i R-$ 30 family is observed in several types of cancer such as breast, bladder, and colon [26, 27]. Moreover, decreased expression of $m i R-30$ is observed in metastasis compared to the primary tumor [28], suggesting a role in aggressive disease. In ATC, $m i R-30$ expression is also reduced in tumor samples [20,29]. Indeed, modulation of $m i R-30$ levels in ATC cells has a great impact in cancer cell biology. Importantly, miR-30d ectopic expression in an ATC cell line reduced monolayer cell growth and impaired anchorage-independent cell growth [30].

Downregulation of $m i R-30$ derepresses the expression of $\mathrm{EZH} 2$, an important component of the polycomb repressive complex 2 (PRC2) that regulates chromatin condensation and gene expression. $\mathrm{EZH} 2$ is the enzymatic subunit of histone methyltransferase that trimethylates histone $\mathrm{H} 3$ lysine 27. EZH2 is overexpressed in ATC and enhances cell proliferation, migration, and invasion, while repressing the expression of thyroid transcription factor PAX8 [31]. Another important cellular process regulated by the $m i R-30$ family is autophagy through targeting the key autophagy-promoting protein, Beclin1 (gene BECN1). In ATC, $m i R-30 d$ restoration sensitizes cancer cells to cisplatin treatment by repressing Beclin1, which participates in the early stages of autophagosome formation [32]. An miR-30d mimic enhanced the apoptotic effects of cisplatin as shown by increased cleaved caspase3 and PARP levels and annexin V staining [33]. Moreover, cisplatin treatment in a xenograft model also showed shrinkage of ATC tumor derived from miR-30 overexpressing cells. The blockage of autophagy using specific inhibitors exerts similar effects to the reintroduction of $m i R-30$ into ATC cells, indicating that the autophagy process is important for ATC cells' resistance to chemotherapy.

2.3. let-7 Family. Family genes of let-7 are located on different chromosomes and are abundantly expressed in a normal thyroid gland (let-7a, let-7b, let-7c, let-7d, let-7e, let-7f, and let-7g) [34]. Deregulation of let-7 is observed in several types of cancer, and its tumor suppressor effects are usually abolished by its downregulation [35]. let-7 was the first miRNA identified as having a role in cancer through validation of RAS protooncogene mRNA targeting and the association of low levels of let-7 with a poor prognosis in lung cancer [36]. Downregulation of several members of the let-7 family is observed in well-differentiated thyroid cancer (PTC and FTC) [37-39], but a marked decrease in the expression of let$7 a$, let-7c, let-7d, let-7f, let-7g, and let-7i is also observed in ATC $[20,21,29]$.

Modulation of let-7 levels alters thyroid cancer cell biology. Ectopic expression of let-7f in a PTC cell line inhibits cell proliferation and viability, while it reduces the activation of MAPK signaling, an important marker of thyroid cancer [40]. Moreover, let-7 enhances the expression of thyroid transcription factor-1 (TTF1/NKX2-1), a key factor in maintaining the expression of iodine metabolizing genes and thyroid 
differentiation, usually lost in ATC. The recovery of let-7a expression in an FTC cell line changes cell morphology to an epithelial-like phenotype (flat and adherent), while it reduces cell migration by targeting FXYD5, an important regulator of cell adhesion [39]. Moreover, in aggressive lung cancer, loss of let-7 is associated with a poorer prognosis [36], and the reduction of $l e t-7 c$ is associated with refractoriness to chemoand radiotherapy treatments. Indeed, the ectopic expression of let-7c in a lung cancer cell line restores the cells' response to chemo- and radiotherapy and represses the EMT process [41], indicating an important role for let-7 in tumor aggressiveness.

\section{Upregulated miRNAs in ATC}

Common miRNAs such as $m i R-146, m i R-221, m i R-222$, and $m i R-17-92$ are upregulated in aggressive ATC and in well-differentiated thyroid cancer, indicating that reinforced expression of these miRNAs is important in maintaining the oncogenic process.

3.1. Cluster miR-17-92. The miR-17-92 cluster is located on chromosome 13 and transcribes a polycistron that yields seven different mature miRNAs: $m i R-17-5 p, m i R-17-3 p$, $m i R-$ 18a, $m i R-19 a, m i R-19 b, m i R-20 a$, and $m i R-92 a$. In normal thyroid follicular cells, early BRAF ${ }^{\mathrm{V} 600 \mathrm{E}}$ oncogene activation induces the expression of an miR-17-92 cluster [42]. The $\mathrm{BRAF}$ oncogene is the most frequent genetic alteration in thyroid cancer (i.e., PTC) and is also detected in ATC, associated with poor clinical-pathological features of cancer such as extrathyroidal invasion, short time recurrence, and distant metastases [43, 44]. High levels of miR-17-92 components are expressed in ATC [45], similar to that observed in other types of cancer, such as lung, colon, pancreatic, and lymphoma [46], especially in the aggressive forms of disease [47].

The molecular modulation of endogenous levels of these miRNAs using LNA (locked nucleic acid) modification resulted in important effects in ATC cell biology. Specific blockage of $m i R-17-5 p, m i R-17-3 p$, and $m i R-19 a$ resulted in a pronounced growth inhibition of ATC cells and apoptosis through activation of caspase-3 and caspase-9 [45]. Inhibition of the miR-17-92 cluster in ATC leads to the recovery of PTEN protein levels [45], an important negative regulator of PI3K growth signaling, which is repressed in ATC. Moreover, among several validated targets for the miR-17-92 cluster are proteins associated with tumor aggressiveness. A key target that influences tumor invasion is TIMP-3, an important inhibitor of metalloproteinase activation, targeted by $m i R-17$ $5 p$ and $m i R-17-3 p$.

3.2. $m i R-146 a$ and $m i R-146 b$. The $m i R-146$ family, $m i R-146 a$ and $m i R-146 b$, is overexpressed in ATC $[18,29,48]$. Despite sharing the same seed region, and therefore targets, $m i R$ $146 a$ and $m i R-146 b$ are transcribed by two independent genes located on chromosomes 5 and 10, respectively, and regulated by the transcription factor $\mathrm{NF} \kappa \mathrm{B}$. The promoter region of both miRNAs contains binding sites for the NFאB complex, part of a key oncogenic signaling pathway, usually overactivated in ATC, which shows increased nuclear staining for
RelA (p65), the subunit of the NFאB dimer [49]. Ectopic expression of the inhibitory protein of this signaling, I $\kappa \mathrm{B}$, decreases miR-146a and miR-146b levels in an ATC cell line [48]. Moreover, inhibition of $m i R-146 a$ leads to an abrogation of anchorage-independent growth and invasion by ATC cells [48]. Interestingly, $\mathrm{NF} \kappa \mathrm{B}$ activation is observed at the invasive front of aggressive PTC showing local invasion compared to the central region of the tumor [50] and also in response to a $\mathrm{BRAF}^{\mathrm{V} 600 \mathrm{E}}$ oncogene, leading to cell migration and invasion [51], and miR-146b upregulation [52]. Moreover, the introduction of $m i R-146 b$ into PTC mutated cells $\left(\mathrm{BRAF}^{\mathrm{V} 600 \mathrm{E}}\right.$ or RET/PTC1) enhances cell invasiveness and migration [53]. Therefore, the $\mathrm{NF} \kappa \mathrm{B}$ signaling pathway and its transcriptionally activated miRNAs, $m i R-146 a$ and $m i R-146 b$, play an important role in thyroid cancer aggressiveness and progression. Indeed, increased plasma circulating levels of miR-146b can be detected in papillary thyroid cancer before surgery, which also correlates with tumor aggressiveness and poor prognosis [54].

3.3. $m i R-221$ and $m i R-222$. $m i R-221 / m i R-222$ is a cluster of miRNAs, located on chromosome $\mathrm{X}$, which is deregulated in thyroid cancer. Although miR-221 and miR-222 overexpression is detected in differentiated (PTC and FTC) $[17,37]$ and anaplastic thyroid cancer cells $[18,29,55]$, the expression of these miRNAs is associated with poor clinical-pathological features of cancer. In PTC and FTC, levels of miR-221 and miR-222 positively correlate with tumor aggressiveness, increased extrathyroidal invasion, tumor size, higher tumor node metastasis stage, and papillary thyroid cancer recurrence $[18,56-58]$. Indeed, higher expression of $m i R-221$ and $m i R-222$ is present in metastatic, in comparison to nonmetastatic, cancers [59]. Moreover, $m i R-222$ increased circulating plasma level is associated with the presence of the BRAF mutation and recurrent papillary thyroid cancer [54].

Ectopic expression of miR-221 in cancer cells results in a robust increase in anchorage-independent growth in softagar medium [37], pointing to a role for this cluster of miRNAs in the process of invasion and cell migration. Indeed, one target of the cluster is RECK, an inhibitor of metalloproteinase. Inhibition of $m i R-221$ impairs cell migration and invasion via upregulation of RECK while it reduces metastases in a colon cancer mouse model [60]. Both miR-221 and miR-222 also influence cell proliferation, once overexpression deregulates the cell cycle, by targeting the $\mathrm{p} 27^{\mathrm{kip} 1}$ (CDKN1B) protein, a key regulator of cell cycle progression [61].

\section{Concluding Remarks}

Currently, there is no effective therapy to blunt the lethal course of ATC, therefore prompting trials of additional and innovative therapies for ATC. Molecular targeted therapy for ATC seems to be a promising approach to retard cancer growth and increase patient survival. The molecular modulation of miRNA levels using miRNA mimics or antimiRs, allied to a novel class of highly specific inhibitors of MAPK and PI3K signaling, for instance, may enhance the ATC response to conventional treatment [62]. 
Systemic miRNA injection has showed promising results using lipid and other carrier molecules for treating lung and prostate cancer in animal models. Intratumoral injection or tail vein injection of a lipid-based miR-34a inhibited orthotopic prostate cancer tumor growth and metastases in immune-deficient mice [63], and lentivirus mediated $m i R$ $34 a$ delivery to prostate cancer cells completely inhibited tumor growth. Moreover, the growth of prostate cancer bone metastases was significantly inhibited by systemically injecting $m i R-16$ complexed with atelocollagen [64]. In lung cancer, systemic injection of a neutral lipid emulsion of $m i R-34 a$ and let-7 significantly decreased in tumor burden in a mouse model of non-small cell lung cancer (NSCLC) [65]. Interestingly, a promising drug called miravirsen (SPC3649) is under phase II clinical trial for treating hepatic cancer. Miravirsen is a 15-nucleotide locked nucleic acid-modified antisense oligonucleotide with high affinity and specificity to $m i R-122$, an miRNA used by HCV for hepatic cells infection [66].

Further studies in vitro and in animal models concerning the functional role of miRNAs and the impact of modulating oncomiR endogenous levels in ATC are one key to their future application as therapeutic adjuvant treatments. In particular, ATC patients would benefit from the concomitant reintroduction of tumor suppressor miRNAs $m i R-200$ and $m i R-30$ and the inhibition of the oncogenic $m i R-146, m i R-$ 221/miR-222, and miR-17-92 clusters, as these miRNAs target several deregulated processes such as cell growth, invasion, migration, and EMT.

\section{Conflict of Interests}

The authors declare that there is no conflict of interests regarding the publication of this paper.

\section{Acknowledgments}

Sao Paulo Research Foundation (FAPESP) Grants nos. 2010/ 51704-0, 2011/50732-2 and 2013/11019-4, a grant from the National Council for Scientific and Technological Development $(\mathrm{CNPq})$, and a grant from the University of Sao Paulo, NapMiR Research Support Center, were presented to this work.

\section{References}

[1] N. Howlader, A. Noone, M. Krapcho et al., Cronin K SEER Cancer Statistics Review, 1975-2011, National Cancer Institute, Bethesda, Md, USA, 2013, based on November 2013 SEER data submission, posted to the SEER web site, April 2014, http://seer .cancer.gov/csr/1975_2011/.

[2] R. C. Smallridge, K. B. Ain, S. L. Asa et al., "American Thyroid Association guidelines for management of patients with anaplastic thyroid cancer," Thyroid, vol. 22, no. 12, pp. 1104-1139, 2012.

[3] J. P. O’Neill and A. R. Shaha, "Anaplastic thyroid cancer," Oral Oncology, vol. 49, no. 7, pp. 702-706, 2013.

[4] K. N. Patel and A. R. Shaha, "Poorly differentiated and anaplastic thyroid cancer," Cancer Control, vol. 13, no. 2, pp. 119-128, 2006.
[5] R. Donghi, A. Longoni, S. Pilotti, P. Michieli, G. Della Porta, and M. A. Pierotti, "Gene p53 mutations are restricted to poorly differentiated and undifferentiated carcinomas of the thyroid gland," Journal of Clinical Investigation, vol. 91, no. 4, pp. 17531760, 1993.

[6] J. A. Fagin, K. Matsuo, A. Karmakar, S. H. Tang, and H. P. Koeffler, "High prevalence of mutations of the p53 gene in poorly differentiated human thyroid carcinomas," The Journal of Clinical Investigation, vol. 91, no. 1, pp. 179-184, 1993.

[7] I. Landa, I. Ganly, TA. Chan et al., "Frequent somatic TERT promoter mutations in thyroid cancer: higher prevalence in advanced forms of the disease," Journal of Clinical Endocrinology and Metabolism, vol. 98, pp. E1562-E1566, 2013.

[8] X. Liu, J. Bishop, Y. Shan et al., "Highly prevalent TERT promoter mutations in aggressive thyroid cancers," EndocrineRelated Cancer, vol. 20, no. 4, pp. 603-610, 2013.

[9] J. C. Ricarte-Filho, M. Ryder, D. A. Chitale et al., "Mutational profile of advanced primary and metastatic radioactive iodinerefractory thyroid cancers reveals distinct pathogenetic roles for BRAF, PIK3CA, and AKT1," Cancer Research, vol. 69, no. 11, pp. 4885-4893, 2009.

[10] R. C. Smallridge, L. A. Marlow, and J. A. Copland, "Anaplastic thyroid cancer: molecular pathogenesis and emerging therapies," Endocrine-Related Cancer, vol. 16, no. 1, pp. 17-44, 2009.

[11] M. N. Nikiforova, E. T. Kimura, M. Gandhi et al., "BRAF mutations in thyroid tumors are restricted to papillary carcinomas and anaplastic or poorly differentiated carcinomas arising from papillary carcinomas," Journal of Clinical Endocrinology and Metabolism, vol. 88, no. 11, pp. 5399-5404, 2003.

[12] G. Garcia-Rostan, G. Tallini, A. Herrero, T. G. D’Aquila, M. L. Carcangiu, and D. L. Rimm, "Frequent mutation and nuclear local-ization of $\beta$-catenin in anaplastic thyroid carcinoma," Cancer Research, vol. 59, no. 8, pp. 1811-1815, 1999.

[13] J. A. Knauf, X. Ma, E. P. Smith et al., "Targeted expression of BRAFV600E in thyroid cells of transgenic mice results in papillary thyroid cancers that undergo dedifferentiation," Cancer Research, vol. 65, no. 10, pp. 4238-4245, 2005.

[14] J. A. Knauf, M. A. Sartor, M. Medvedovic et al., "Progression of BRAF-induced thyroid cancer is associated with epithelialmesenchymal transition requiring concomitant MAP kinase and TGFB signaling," Oncogene, vol. 30, no. 28, pp. 3153-3162, 2011.

[15] D. G. McFadden, A. Vernon, P. M. Santiago et al., "p53 constrains progression to anaplastic thyroid carcinoma in a Brafmutant mouse model of papillary thyroid cancer," Proceedings of the National Academy of Sciences of the United States of America, vol. 111, no. 16, pp. E1600-E1609, 2014.

[16] V. G. Antico Arciuch, M. A. Russo, M. Dima et al., "Thyrocytespecific inactivation of $\mathrm{p} 53$ and Pten results in anaplastic thyroid carcinomas faithfully recapitulating human tumors," Oncotarget, vol. 2, no. 12, pp. 1109-1126, 2011.

[17] H. He, K. Jazdzewski, W. Li et al., "The role of microRNA genes in papillary thyroid carcinoma," Proceedings of the National Academy of Sciences of the United States of America, vol. 102, no. 52, pp. 19075-19080, 2005.

[18] M. N. Nikiforova, G. C. Tseng, D. Steward, D. Diorio, and Y. E. Nikiforov, "MicroRNA expression profiling of thyroid tumors: biological significance and diagnostic utility," Journal of Clinical Endocrinology and Metabolism, vol. 93, no. 5, pp. 1600-1608, 2008. 
[19] C. Ferraz, S. Lorenz, B. Wojtas, S. R. Bornstein, R. Paschke, and M. Eszlinger, "Inverse correlation of miRNA and cell cycleassociated genes suggests influence of miRNA on benign thyroid nodule tumorigenesis," Journal of Clinical Endocrinology and Metabolism, vol. 98, E8, no. 1, p. E16, 2013.

[20] R. Visone, P. Pallante, A. Vecchione et al., "Specific microRNAs are downregulated in human thyroid anaplastic carcinomas," Oncogene, vol. 26, no. 54, pp. 7590-7595, 2007.

[21] J. Braun, C. Hoang-Vu, H. Dralle, and S. Hüttelmaier, "Downregulation of microRNAs directs the EMT and invasive potential of anaplastic thyroid carcinomas," Oncogene, vol. 29, no. 29, pp. 4237-4244, 2010.

[22] C. J. Chang, C. H. Chao, W. Xia et al., "p53 regulates epithelialmesenchymal transition and stem cell properties through modulating miRNAs," Nature Cell Biology, vol. 13, pp. 317-323, 2011.

[23] H. Hermeking, "MicroRNAs in the p53 network: micromanagement of tumour suppression," Nature Reviews Cancer, vol. 12, no. 9, pp. 613-626, 2012.

[24] B. A. Schiff, A. B. McMurphy, S. A. Jasser et al., "Epidermal growth factor receptor (EGFR) is overexpressed in anaplastic thyroid cancer, and the EGFR inhibitor gefitinib inhibits the growth of anaplastic thyroid cancer," Clinical Cancer Research, vol. 10, no. 24, pp. 8594-8602, 2004.

[25] Z. Zhang, Z. Liu, W. Ren, X. Ye, and Y. Zhang, "The miR-200 family regulates the epithelial-mesenchymal transition induced by EGF/EGFR in anaplastic thyroid cancer cells," International Journal of Molecular Medicine, vol. 30, no. 4, pp. 856-862, 2012.

[26] T. Ichimi, H. Enokida, Y. Okuno et al., "Identification of novel microRNA targets based on microRNA signatures in bladder cancer," International Journal of Cancer, vol. 125, no. 2, pp. 345352, 2009.

[27] M. Ouzounova, T. Vuong, P. Ancey et al., "MicroRNA miR-30 family regulates non-attachment growth of breast cancer cells," BMC Genomics, vol. 14, article 139, 2013.

[28] R. Baffa, M. Fassan, S. Volinia et al., "MicroRNA expression profiling of human metastatic cancers identifies cancer gene targets," The Journal of Pathology, vol. 219, no. 2, pp. 214-221, 2009.

[29] S. Schwertheim, S. Sheu, K. Worm, F. Grabellus, and K. W. Schmid, "Analysis of deregulated miRNAs is helpful to distinguish poorly differentiated thyroid carcinoma from papillary thyroid carcinoma," Hormone and Metabolic Research, vol. 41, no. 6, pp. 475-481, 2009.

[30] F. Esposito, M. Tornincasa, P. Pallante et al., "Down-regulation of the miR-25 and miR-30d contributes to the development of anaplastic thyroid carcinoma targeting the polycomb protein EZH2," Journal of Clinical Endocrinology and Metabolism, vol. 97, no. 5, pp. E710-E718, 2012.

[31] E. Borbone, G. Troncone, A. Ferraro et al., "Enhancer of zeste homolog 2 overexpression has a role in the development of anaplastic thyroid carcinomas," Journal of Clinical Endocrinology and Metabolism, vol. 96, no. 4, pp. 1029-1038, 2011.

[32] H. Zhu, H. Wu, X. Liu et al., "Regulation of autophagy by a beclin 1-targeted microRNA, miR-30a, in cancer cells," Autophagy, vol. 5, no. 6, pp. 816-823, 2009.

[33] Y. Zhang, W. Q. Yang, H. Zhu et al., "Regulation of autophagy by miR-30d impacts sensitivity of anaplastic thyroid carcinoma to cisplatin," Biochemical Pharmacology, vol. 87, pp. 562-570, 2014.

[34] F. Marini, E. Luzi, and M. L. Brandi, "MicroRNA role in thyroid cancer development," Journal of Thyroid Research, vol. 2011, Article ID 407123, 12 pages, 2011.
[35] C. S. Fuziwara, M. V. Geraldo, and E. T. kimura, "Let-7 and cancer," in MicroRNA Let-7: Role in Human Diseases and Drug Discovery, N. Dahiya, Ed., pp. 109-124, Nova Science Publishers, New York, NY, USA, 2012.

[36] J. Takamizawa, H. Konishi, K. Yanagisawa et al., "Reduced expression of the let-7 microRNAs in human lung cancers in association with shortened postoperative survival," Cancer Research, vol. 64, no. 11, pp. 3753-3756, 2004.

[37] P. Pallante, R. Visone, M. Ferracin et al., "MicroRNA deregulation in human thyroid papillary carcinomas," Endocrine-Related Cancer, vol. 13, no. 2, pp. 497-508, 2006.

[38] M. Swierniak, A. Wojcicka, M. Czetwertynska et al., "In-depth characterization of the MicroRNA transcriptome in normal thyroid and papillary thyroid carcinoma," Journal of Clinical Endocrinology and Metabolism, vol. 98, no. 8, pp. E1401-E1409, 2013.

[39] M. Colamaio, G. Calì, D. Sarnataro et al., "Let-7a down regulation plays a role in thyroid neoplasias of follicular histotype affecting cell adhesion and migration through its ability to target the FXYD5 (Dysadherin) gene," Journal of Clinical Endocrinology and Metabolism, vol. 97, no. 11, pp. E2168-E2178, 2012.

[40] J. C. M. Ricarte-Filho, C. S. Fuziwara, A. S. Yamashita, E. Rezende, M. J. da-Silva, and E. T. Kimura, "Effects of let-7 microRNA on cell growth and differentiation of papillary thyroid cancer," Translational Oncology, vol. 2, no. 4, pp. 236-241, 2009.

[41] S. Y. Cui, J. Y. Huang, Y. T. Chen et al., "Let-7c governs the acquisition of chemo- or radioresistance and epithelial-tomesenchymal transition phenotypes in docetaxel-resistant lung adenocarcinoma," Molecular Cancer Research, vol. 11, no. 7, pp. 699-713, 2013.

[42] C. S. Fuziwara and E. T. Kimura, "High iodine blocks a Notch/miR-19 loop activated by the BRAFV600E oncoprotein and restores the response to TGFbeta in thyroid follicular cells," Thyroid, vol. 24, no. 3, pp. 453-462, 2013.

[43] G. Riesco-Eizaguirre, P. Gutiérrez-Martínez, M. A. GarcíaCabezas, M. Nistal, and P. Santisteban, "The oncogene $\mathrm{BRAF}^{V 600 E}$ is associated with a high risk of recurrence and less differentiated papillary thyroid carcinoma due to the impairment of $\mathrm{Na}^{+} / \mathrm{I}^{-}$targeting to the membrane," Endocrine-Related Cancer, vol. 13, no. 1, pp. 257-269, 2006.

[44] M. Xing, W. H. Westra, R. P. Tufano et al., "BRAF mutation predicts a poorer clinical prognosis for papillary thyroid cancer," Journal of Clinical Endocrinology and Metabolism, vol. 90, no. 12, pp. 6373-6379, 2005.

[45] S. Takakura, N. Mitsutake, M. Nakashima et al., "Oncogenic role of miR-17-92 cluster in anaplastic thyroid cancer cells," Cancer Science, vol. 99, no. 6, pp. 1147-1154, 2008.

[46] S. Volinia, G. A. Calin, C. Liu et al., "A microRNA expression signature of human solid tumors defines cancer gene targets," Proceedings of the National Academy of Sciences of the United States of America, vol. 103, no. 7, pp. 2257-2261, 2006.

[47] Y. Hayashita, H. Osada, Y. Tatematsu et al., "A polycistronic MicroRNA cluster, miR-17-92, is overexpressed in human lung cancers and enhances cell proliferation," Cancer Research, vol. 65, no. 21, pp. 9628-9632, 2005.

[48] F. Pacifico, E. Crescenzi, S. Mellone et al., "Nuclear factor- $\kappa b$ contributes to anaplastic thyroid carcinomas through up-regulation of miR-146a," Journal of Clinical Endocrinology and Metabolism, vol. 95, no. 3, pp. 1421-1430, 2010. 
[49] F. Pacifico, C. Mauro, C. Barone et al., "Oncogenic and antiapoptotic activity of NF- $\kappa \mathrm{B}$ in human thyroid carcinomas," The Journal of Biological Chemistry, vol. 279, no. 52, pp. 5461054619, 2004.

[50] V. Vasko, A. V. Espinosa, W. Scouten et al., "Gene expression and functional evidence of epithelial-to-mesenchymal transition in papillary thyroid carcinoma invasion," Proceedings of the National Academy of Sciences of the United States of America, vol. 104, no. 8, pp. 2803-2808, 2007.

[51] I. Palona, H. Namba, N. Mitsutake et al., "BRAFV600E promotes invasiveness of thyroid cancer cells through nuclear factor $\kappa$ B activation," Endocrinology, vol. 147, no. 12, pp. 56995707, 2006.

[52] M. V. Geraldo, A. S. Yamashita, and E. T. Kimura, "MicroRNA miR-146b-5p regulates signal transduction of TGF-B by repressing SMAD4 in thyroid cancer," Oncogene, vol. 31, no. 15, pp. 1910-1922, 2012.

[53] C. Chou, K. D. Yang, F. Chou et al., "Prognostic implications of miR-146b expression and its functional role in papillary thyroid carcinoma," The Journal of Clinical Endocrinology and Metabolism, vol. 98, no. 2, pp. E196-E205, 2013.

[54] J. C. Lee, J. T. Zhao, R. J. Clifton-Bligh et al., "MicroRNA-222 and microRNA-146b are tissue and circulating biomarkers of recurrent papillary thyroid cancer," Cancer, vol. 119, no. 24, pp. 4358-4365, 2013.

[55] S. Mitomo, C. Maesawa, S. Ogasawara et al., "Downregulation of miR-138 is associated with overexpression of human telomerase reverse transcriptase protein in human anaplastic thyroid carcinoma cell lines," Cancer Science, vol. 99, no. 2, pp. 280-286, 2008.

[56] C. K. Chou, R. F. Chen, F. F. Chou et al., "MiR-146b is highly expressed in adult papillary thyroid carcinomas with high risk features including extrathyroidal invasion and the BRAF ${ }^{V 600 E}$ mutation," Thyroid, vol. 20, no. 5, pp. 489-494, 2010.

[57] Z. Wang, H. Zhang, L. He et al., "Association between the expression of four upregulated miRNAs and extrathyroidal invasion in papillary thyroid carcinoma," OncoTargets and Therapy, vol. 6, pp. 281-287, 2013.

[58] J. C. Lee, J. T. Zhao, R. J. Clifton-Bligh et al., "MicroRNA-222 and MicroRNA-146b are tissue and circulating biomarkers of recurrent papillary thyroid cancer," Cancer, vol. 119, no. 24, pp. 4358-4365, 2013.

[59] T. Jikuzono, M. Kawamoto, H. Yoshitake et al., "The miR221/ 222 cluster, miR-10b and miR-92a are highly upregulated in metastatic minimally invasive follicular thyroid carcinoma," International Journal of Oncology, vol. 42, no. 6, pp. 1858-1868, 2013.

[60] J. Qin and M. Luo, "MicroRNA-221 promotes colorectal cancer cell invasion and metastasis by targeting RECK," FEBS letters, vol. 588, no. 1, pp. 99-104, 2014.

[61] R. Visone, L. Russo, P. Pallante et al., "MicroRNAs (miR)-221 and miR-222, both overexpressed in human thyroid papillary carcinomas, regulate p27Kip1 protein levels and cell cycle," Endocrine-Related Cancer, vol. 14, no. 3, pp. 791-798, 2007.

[62] C. S. Fuziwara and E. T. Kimura, "Modulation of deregulated microRNAs for target therapy in thyroid cancer," in MicroRNA Targeted Cancer Therapy, F. H. Sarkar, Ed., pp. 219-237, Springer, Cham, Switzerland, 1st edition, 2014.

[63] C. Liu, K. Kelnar, B. Liu et al., "The microRNA miR-34a inhibits prostate cancer stem cells and metastasis by directly repressing CD44," Nature Medicine, vol. 17, no. 2, pp. 211-215, 2011.
[64] F. Takeshita, L. Patrawala, M. Osaki et al., "Systemic delivery of synthetic microRNA-16 inhibits the growth of metastatic prostate tumors via downregulation of multiple cell-cycle genes," Molecular Therapy, vol. 18, no. 1, pp. 181-187, 2010.

[65] P. Trang, J. F. Wiggins, C. L. Daige et al., "Systemic delivery of tumor suppressor microRNA mimics using a neutral lipid emulsion inhibits lung tumors in mice," Molecular Therapy, vol. 19, no. 6, pp. 1116-1122, 2011.

[66] H. L. A. Janssen, H. W. Reesink, E. J. Lawitz et al., "Treatment of HCV infection by targeting microRNA," The New England Journal of Medicine, vol. 368, no. 18, pp. 1685-1694, 2013.

[67] T. Vergoulis, I. S. Vlachos, P. Alexiou et al., “TarBase 6.0: capturing the exponential growth of miRNA targets with experimental support," Nucleic Acids Research, vol. 40, no. 1, pp. D222-D229, 2012.

[68] S. M. Johnson, H. Grosshans, J. Shingara et al., "RAS is regulated by the let-7 microRNA family," Cell, vol. 120, no. 5, pp. 635-647, 2005.

[69] D. Wu, J. Ding, L. Wang et al., "MicroRNA-125b inhibits cell migration and invasion by targeting matrix metallopeptidase 13 in bladder cancer," Oncology Letters, vol. 5, no. 3, pp. 829-834, 2013.

[70] K. Jazdzewski, J. Boguslawska, J. Jendrzejewski et al., “Thyroid hormone receptor $\beta$ (THRB) is a major target gene for microRNAs deregulated in papillary thyroid carcinoma (PTC)," Journal of Clinical Endocrinology and Metabolism, vol. 96, no. 3, pp. E546-E553, 2011.

[71] D. Bhaumik, G. K. Scott, S. Schokrpur, C. K. Patil, J. Campisi, and C. C. Benz, "Expression of microRNA-146 suppresses NF$\kappa \mathrm{B}$ activity with reduction of metastatic potential in breast cancer cells," Oncogene, vol. 27, no. 42, pp. 5643-5647, 2008. 


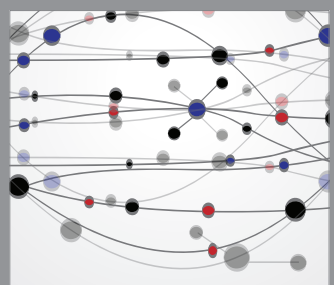

The Scientific World Journal
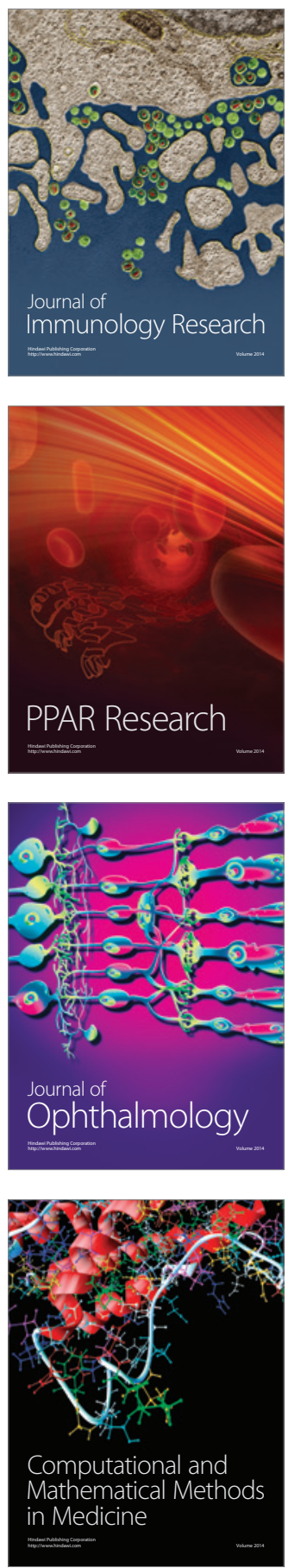

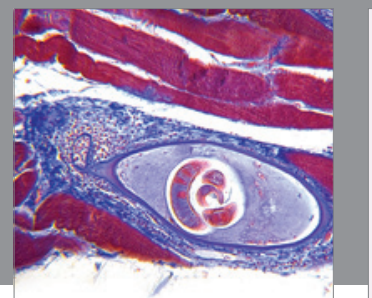

Gastroenterology

Research and Practice
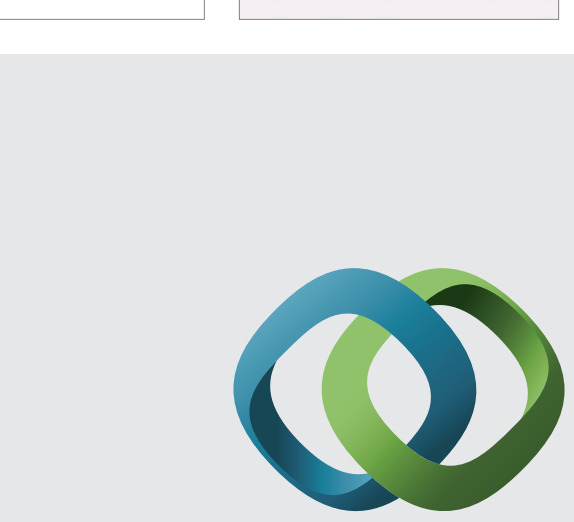

\section{Hindawi}

Submit your manuscripts at

http://www.hindawi.com
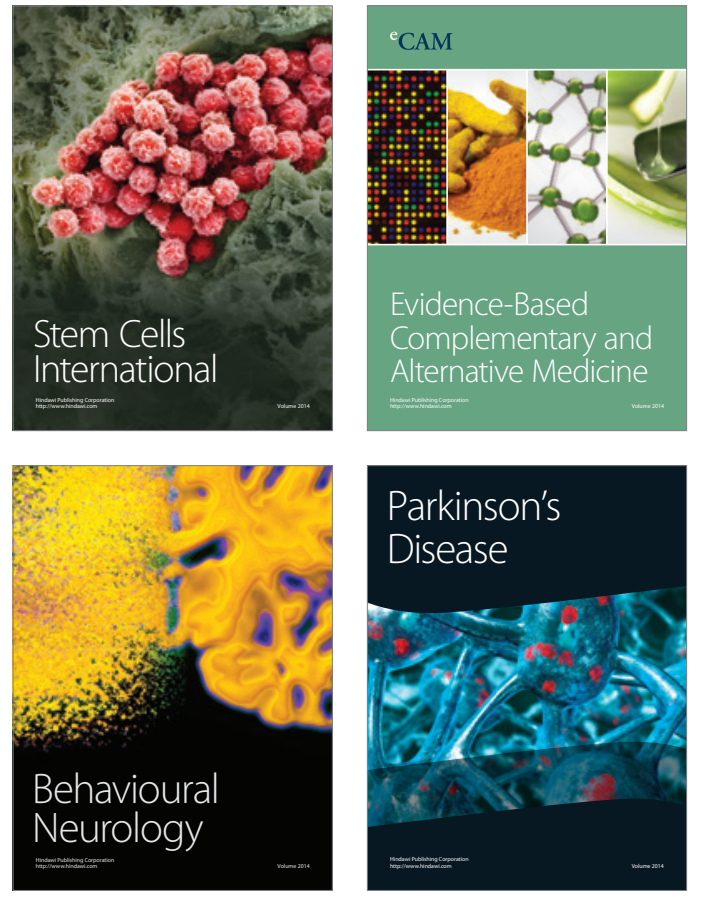
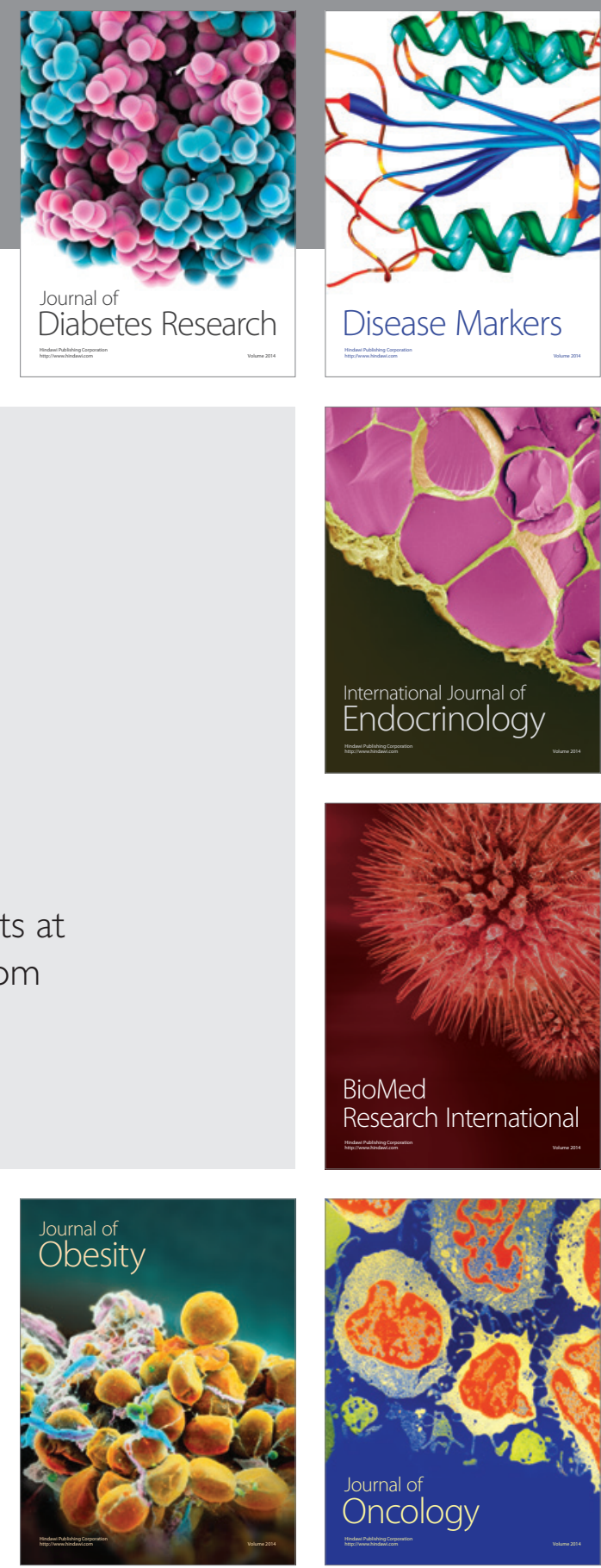

Disease Markers
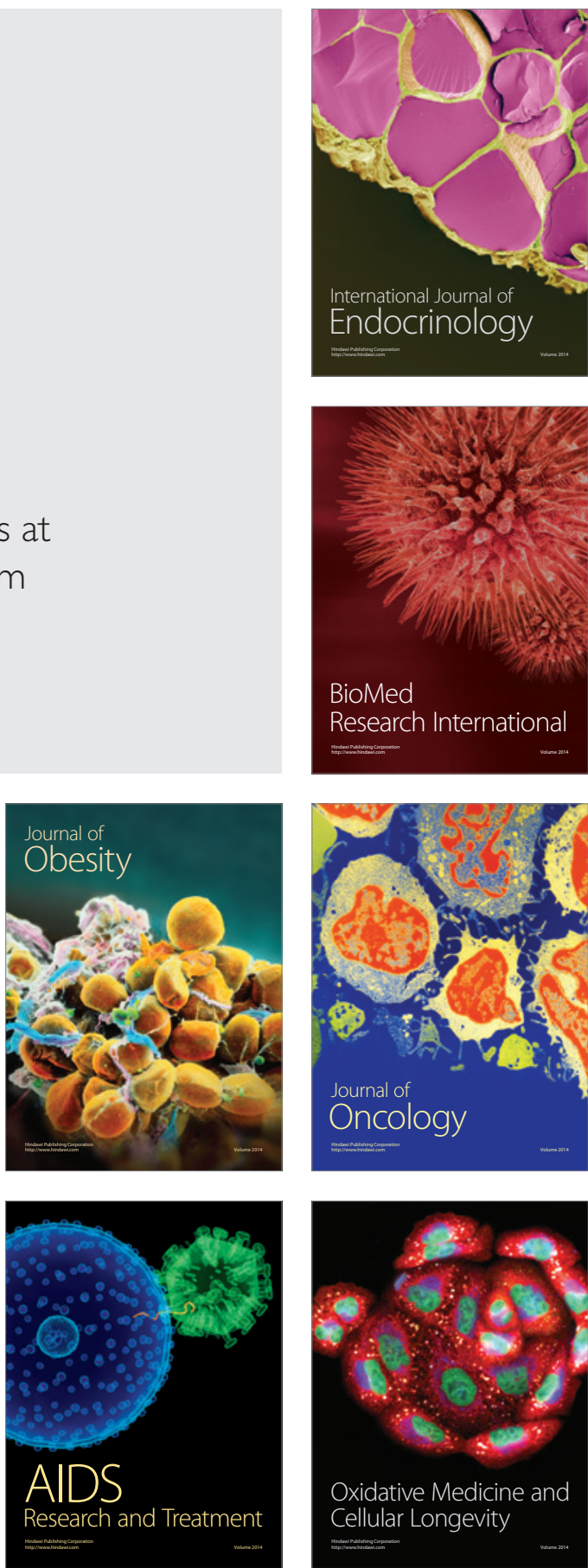